\title{
Comunicação e consumo nas dinâmicas culturais do mundo globalizado
}

\section{Comunicación y consumo en las dinámicas culturales del mundo globalizado}

\section{Communication and consumption in the cultural dynamics of the globalized world}

\author{
Gisela G. S. Castro ${ }^{1}$
}

Palavras chave:

Consumo

Sociedade de Consumo

Consumidor
Resumo:

No conjunto dos estudos multidisciplinares que caracterizam o campo da Comunicação, o consumo tornou-se um tema de destaque que tem merecido análises a partir de diferentes perspectivas teóricometodológicas. Como denominador comum, entende-se que se trata de um vetor central na constituição da experiência contemporânea num mundo crescentemente regido por processos de globalização econômica e cultural. A principal motivação deste artigo é oferecer uma cartografia comentada das principais vertentes dos estudos do consumo nas ciências sociais. Pretende-se desse modo chamar a atenção para essa temática de investigação e dar a conhecer algumas das reflexões no campo ao dialogar com o oportuno tema selecionado pelos editores para este dossiê de Pragmatizes, a saber: cultura e práticas de consumo. 


\section{Resumen:}

En el conjunto de los estudios multidisciplinares que caracterizan el campo de la Comunicación, el consumo se ha tornado un tema prominente que ha merecido análisis desde diferentes perspectivas teórico-metodológicas. Como denominador común, se entiende que se trata de un vector central en la constitución de la experiencia contemporánea en un mundo cada vez más regido por procesos de globalización económica y cultural. La principal motivación de este artículo es ofrecer una cartografía comentada de las principales vertientes de los estudios del consumo en las ciencias sociales. De ese modo, se pretende llamar la atención sobre este tema de investigación y dar a conocer algunas de las reflexiones en el campo al dialogar con el oportuno tema seleccionado por los editores para este expediente de Pragmatizes, a saber: cultura y prácticas de consumo.

Palabras clave:

Consumo

Sociedad de consumo

Consumidor

\section{Keywords:}

Consumption

Consumer society

Consumer

\section{Abstract:}

In the set of the multidisciplinary studies that characterize the field of Communication, consumption has become a prominent theme which deserves analyses from different theoretical and methodological perspectives. As a common denominator, it is understood that it is a central vector in the constitution of the contemporary experience in a world increasingly ruled by processes of economic and cultural globalization. The main motivation of this article is to offer a commented cartography of the main strands of the consumption studies in the social sciences. It is intended thereby to draw attention to this theme of research and report some of the reflections in the field by dealing with the opportune theme selected by the editors for this dossier of Pragmatizes, namely culture and consumption practices. 


\section{Comunicação e consumo nas dinâmicas culturais do mundo globalizado}

\section{Introdução}

Embora em sua acepção weberiana a expressão 'sociedade de consumo' se referisse ao modo como se organiza o suprimento das necessidades diárias no sistema capitalista, seu uso mais comumente disseminado seve para designar - geralmente de modo pejorativo as sociedades ocidentais pós Segunda Grande Guerra. Entretanto, é sempre bom lembrar que as práticas de consumo já faziam parte do modo de vida, notadamente dos socialmente privilegiados, desde muito tempo. A história da cultura ocidental localiza no gosto por especiarias e mercadorias exóticas um dos principais impulsos para as Grandes Navegações. O estabelecimento de rotas marítimas que consolidaram o comércio regular com o Oriente redesenhou as práticas mercantis e a vida nas cortes europeias. A descoberta do Novo Mundo, que alguns à época acreditaram tratar-se do Paraíso na Terra, forneceu novo ímpeto a mudanças que vinham ocorrendo há tempos e tomaram forma na modernidade.

As origens da implementação do consumo como parte das práticas cotidianas das camadas mais amplas da população teria ocorrido na Europa do final do século XVIII. Nesta 'revolução do consumo', que se estendeu até o século seguinte, bens antes restritos às classes dominantes - como, por exemplo, roupas e acessórios - se tornam acessíveis aos menos abastados graças a mudanças profundas nos modos de produção e de sua apresentação como objetos de contemplação em vitrines, galerias e grandes magazines.
A ascensão do consumo como parte integrante do modo de vida moderno se intensifica na segunda metade do século XIX e está diretamente associada à emergência de novas técnicas de exposição e venda, à expansão da produção e do crédito, bem como aos apelos crescentes da publicidade, que se sofistica. Esses e outros fatores transformaram as compras em passeio agradável, socialmente bem aceito e relevante. Embora se deva ressaltar que o consumo não se resuma ao ato de compra, e embora o 'ir às compras' não necessariamente resulte na aquisição de serviços ou mercadorias, fazer compras requer uma série de saberes e competências que demandam forte engajamento e intensa pedagogia social. A sistemática (re)organização dos espaços e dinâmicas do consumo nas rotinas de trabalho e lazer, tem efeito a consolidação da cultura do consumo e sua predominância no contemporâneo. Hoje entende-se a cultura como campo plural, notadamente permeado por processos de negociação e disputa. Sendo assim, a rigor não seria correto falarmos em cultura, mas culturas do consumo.

Diferente da exacerbação da orgia consumista, o consumo deve ser entendido como o resultado de um conjunto de práticas sociais e culturais fortemente relacionados às subjetividades dos atores e ao grupo social ao qual pertencem. Imersos nessas culturas do consumo, nós criamos identificações, construímos identidades, reconhecemos nossos pares e somos reconhecidos socialmente. Quando consumimos, não estamos apenas admirando, adquirindo ou utilizando determinado produto ou serviço. Estamos comunicando algo e criando relações com tudo e todos os que estão à nossa volta.

Ressaltamos a inter-relação social entre comunicação e consumo nos mais diversos processos cotidianos. A 
rigor, cada ato de consumo é também, simultaneamente, um ato de comunicação. Por meio das escolhas que fazemos sobre como organizar e preencher o espaço onde vivemos, como nos vestimos, os lugares que frequentamos, as comidas que elegemos e as que rejeitamos, dentre outras escolhas, criamos significados e alimentamos circuitos simbólicos.

Sendo assim, nossas práticas de consumo vão muito além do aspecto material, pois o que comunicamos se torna simbólico, representativo de um estilo de vida, uma maneira de ser e de agir. Sob este ponto de vista, Sodré (2006: 56) argumenta que houve uma mutação capitalista, também chamada de 'nova economia' na qual "a dimensão imaterial da mercadoria prevalece sobre sua materialidade, tornando o valor social ou estético maior do que o valor de uso e o valor de troca". Dito de outro modo: na contemporaneidade o consumo simbólico superou em significação o consumo material, atingindo uma relevância sem precedentes. Nessa linha de argumentação, evidencia-se o aspecto propriamente cultural das mais diversas práticas de consumo.

Protagonista no entendimento do consumo como fenômeno complexo de cunho sociocultural, Mike Featherstone (1990) identifica três principais abordagens no desenvolvimento desse campo de estudos, que passaremos a discutir a seguir. Na primeira delas o consumo é examinado a partir das demandas e ritmos da produção em série. Nessas análises, o consumo capitalista resulta da manipulação das massas a partir de técnicas persuasivas de caráter ideológico e disciplinar a serviço das estruturas hegemônicas de poder. Na segunda abordagem, o fenômeno do consumo já não é mais enfeixado como um todo homogêneo, mas passa a ser examinado a par- tir de práticas específicas que informam sobre modos distintos de apropriação e atribuição de sentido e valor. Por fim, a terceira abordagem diz respeito ao caráter afetivo do jorro irrefreável de imagens e narrativas do consumo na contemporaneidade. Discute-se a transformação da experiência em mercadoria e o viés ético e estético do universo simbólico das marcas na modulação das subjetividades contemporâneas.

\section{A Escola de Frankfurt e a constituição do consumidor moderno}

A formação marxista dos pensadores da Escola de Frankfurt levou-os a voltar sua atenção para o caráter coercitivo da constituição ideológica e da sedução publicitária no adestramento social do consumidor, entendido como um ser disciplinado e passivo. Ao examinarem a expansão da produção capitalista no âmbito da cultura de massas, Adorno e Horkheimer destacaram os processos de reificação da mercadoria e a alienação do consumidor como parte da ideologia constituinte da ideia de qualidade na vida moderna. Na pedagogia social vigente, associa-se este ideário à posse de bens e produtos como automóveis e eletrodomésticos, por exemplo, apresentados como indispensáveis para uma vida arrojada, confortável e plena.

Adorno e Horkheimer criaram o conceito de indústria cultural na intenção de sublinhar o caráter ideológico da cultura de produção em série voltada para as massas. A seu ver, produtos culturais homogêneos destinados a atrelar o lazer à docilização do entretenimento ${ }^{2}$ representavam uma ameaça à liberdade e à capacidade crítica do trabalhador, reduzido ao uso instrumental das faculdades da razão nas esferas do trabalho e do lazer, igualmente alienantes. Embora reconheçam sua inegável contri- 
buição, críticas a essa perspectiva destacam o caráter elitista e nostálgico da concepção de alta cultura dos teóricos de Frankfurt, bem como sua dificuldade em detectar o caráter ativo das práticas de consumo, as quais serão examinadas mais adiante no próximo tópico desta discussão.

Algum tempo depois e também fortemente influenciada pela tradição marxista, notadamente as ideias de Lukács e Lefebvre, a análise de Baudrillard sobre a lógica da mercadoria levou a um melhor entendimento sobre o caráter sígnico dos bens de consumo. Nessa concepção, o consumo surge como um ritual de manipulação ativa de signos, por meio das 'mercadorias-signo'. A ênfase da semiologia nos movimentos de atribuição de sentido evidencia uma guinada da perspectiva material em direção a uma abordagem mais propriamente cultural do fenômeno do consumo. Em trabalhos subsequentes, Baudrillard iria continuar nesta direção ao insistir que a exacerbada proliferação de signos leva a uma lógica da simulação e da reprodução contínua. Nesse contexto, o fascinante jorro de imagens veiculadas pela mídia tornaria crescentemente indiscerníveis simulacro e realidade.

Ainda dentro do paradigma marxista, pensadores como Frederic Jameson realizam influentes trabalhos sobre as lógicas de produção no capitalismo tardio, também denominado capitalismo pós industrial ou de consumo. Para este e outros autores da pós-modernidade, a predominância do aspecto cultural nas dinâmicas sociais caracteriza a sociedade de consumo, a qual está diretamente relacionada com a condição pós moderna. A perspectiva pós moderna tende a responsabilizar o crescente individualismo e o dispersivo fascínio da volúpia consumista pelo desengajamento dos sujeitos no espaço público e pelos desregramentos decorrentes no campo social.

Como objeto de estudo, o consumo foi durante muito tempo obliterado pelo preconceito reinante no meio acadêmico que destacava a produção como valor supremo e atribuía ao consumo a frívola acepção de'conspícuo, chegando à sua descaracterização na pecha do displicente'consumismo'. É fundamental que seja feita a devida delimitação conceitual entre consumo e consumismo. Entende-se aqui esse último como exacerbação voraz e frequentemente irrefreável do primeiro. Nesses termos, o consumismo se afigura como um contumaz e insensato padrão de consumo, o frenesi da aquisição (aparentemente) ilimitada e da conspícua acumulação de produtos e marcas.

Embora se reconheça o consumismo como condição persistente em nossos tempos, é preciso ir além da visão restrita sobre o consumidor submetido, sem reação, aos interesses dominantes. Essa concepção do consumidor alienado, sem condições de decisão e totalmente cooptado pelo consumismo; um ser egoísta e autocentrado que só almeja a satisfação de seus próprios desejos não estaria mais de acordo com a dinâmica da realidade contemporânea. Exames mais detalhados acerca das lógicas de consumo revelam a especificidade nos modos de apropriação de diversos bens de consumo por parte de diferentes grupos sociais. Esses estudos dão origem à segunda abordagem mencionada por Featherstone (1990), que se volta para a análise das práticas de consumo.

\section{Os significado dos bens e as práticas de consumo}

Entender as práticas de consumo implica em observar de que modo os bens funcionam como linguagem, comunican- 
do sinais de distinção e classificação em um meio social altamente mediado pelos signos do consumo. Estudar as práticas de consumo significa também procurar compreender as especificidades dos modos de apropriação de cada grupo social, que funciona segundo regras próprias de atribuição de sentido a produtos, serviços, marcas e afins. Análises de cunho sociológico e etnográfico das práticas de consumo hoje servem também como insumo para a prospecção mercadológica dos desejos e idiossincrasias do consumidor, em um mercado cada vez mais segmentado e competitivo.

A esse respeito, vale mencionar o significativo valor comercial do vasto cabedal de informações disponibilizadas pelos usuários das redes sociais digitais sobre seus hábitos e preferências de consumo. O monitoramento e o processamento desses dados no escrutínio corporativo do user-generated content ${ }^{3}$ permite ao mercado calibrar a produção segundo demandas e preferências dos consumidores.

Análises da dimensão cultural das práticas de consumo levam em consideração, de um lado, a simbologia atrelada aos bens por meio de suas múltiplas camadas de significado: composição, modo de produção, embalagem, marca, circuito de distribuição etc. Por outro lado, é igualmente importante examinaras mudanças de significado atribuídos aos bens de consumo em cada situação, por diferentes tipos de consumidores, nas diversas etapas da 'vida social' dos bens.

A título de exemplo,nos diferentes mecanismos de construção e legitimação de mercados vale ressaltar as transformações resultantes da introdução de técnicas científicas de manipulação do vinho após a fase agrícola, as alianças e enfrentamentos entre produtores de diferentes regiões em âmbito nacional e internacional,incentivos de governo e barreiras tarifárias no comércio exterior, o papel dos especialistas na constituição de novos parâmetros de gosto e tantos outros fatores que influenciam direta ou indiretamente o consumo desta icônica bebida.

No que tange às transformações costumeiras na vida social do vinho como um produto, podemos citar a notável variação na atribuição de significado e valor para o vinho que acabou de ser produzido e aquele já envelhecido apropriadamente. Não obstante os esforços de certos produtores em legitimar, por exemplo, o beaujolais noveau ao promoverem grande expectativa em torno das primeiras remessas de cada safra, a tradição vinícola designa a maturação como uma pátina necessária e desejável na produção e valorização do produto. Para muitos especialistas, portanto, qualificar um vinho como 'novo' ou 'jovem' em geral significa identificar na bebida atributos que serão melhor resolvidos no devido tempo, desde que observadas as condições adequadas para a sua conservação e manipulação.

Continuando o exemplo acima, consideremos a seguir uma hipotética garrafa compartilhada com amigos durante um jantar. A despeito de ter sido adquirida pelos donos da casa ou trazida de presente pelos convidados, não é a bebida igualmente consumida por todos os presentes? E quanto àquela garra$\mathrm{fa}^{4}$ zelosamente guardada pelo colecionador $^{5}$ e que jamais é aberta: não seria também consumida, embora de outro modo? Apesar de indistintos no senso comum - assim como em certos manuais de marketing, cabe a importante delimitação conceitual entre consumir, adquirir e comprar. Como vimos, pode-se consumir sem adquirir. Comprar é apenas uma forma de adquirir algo, embora seja talvez a mais comum nas culturas do consumo. Afinal, há vários outros meios lícitos e ilí- 
citos de se adquirir algo, como por herança, empréstimo e outros.

Mudando o campo das materialidades mas ainda dentro do universo semântico do consumo, consideremos as seguintes situações. Se compramos um livro que, por qualquer motivo não lemos: pode-se dizer que houve consumo? E se lemos um livro emprestado - por amigo ou biblioteca? O empréstimo desconfiguraria a leitura como forma de consumo?

Evidentemente, ao explorar sua conceituação devemos entender o consumo como atividade enraizada em práticas sociais. Nesse contexto, deve-se considerar aspectos como modo de aquisição, materialidades e, dentre outros aspectos, a própria experiência do consumo com toda a riqueza simbólica que configura cada qual como sendo única. Vistas de perto, as práticas de consumo revelam-se muito mais matizadas do que indicavam os estudos vistos sob a ótica da produção. Enfocadas no conjunto das táticas e astúcias do cotidiano, conforme Michel de Certeau, as práticas de consumo informam sobre questões étnicas, geracionais, de gênero e classe social, dentre outras. Ademais, elas ajudam a configurar nossa experiência de mundo.

Segundo Alonso (2007:99), ao entender o consumidor como sendo

"portador de percepções, representações e valores que se integram e completam com o resto de seus âmbitos e esferas de atividade, passamos a perceber o processo de consumo como um conjunto de comportamentos que recolhem e ampliam, no âmbito privado dos estilos de vida, as mudanças culturais da sociedade em seu conjunto".

Examinando-se, por exemplo, as práticas de consumo midiático pode-se tecer considerações sobre a atribuição de valor em diferentes segmentos sociais transformados em nichos ou clusters de mercado. Em meio à produção generalizada e ao acesso facilitado a bens de consumo que poderiam sinalizar status ou pertencimento a segmentos privilegiados, a desenvoltura no uso ganha proeminência. A questão que se impõe é o papel desempenhado por esse tipo de consumo como elemento de vinculação e distinção social.

No campo da moda atual, por exemplo, já não se trata tanto do que escolher para vestir em cada situação, mas do modo como cada um se comporta com a roupa e os acessórios que está usando. Como nos mecanismos de distinção fartamente descritos por Bourdieu, entra em jogo o capital simbólico na constituição não apenas da aparência como também da atitude considerada adequada. Todo um repertório de saberes, familiaridade e acesso a instâncias legitimadoras torna possível detectar e desmascarar arrivistas e impostores. Segundo Featherstone (1990: 12), trata-se do contraste entre uma espécie de 'cultura incorporada' e o autodidatismo (es)forçado dos recém chegados. Na trama social do gosto continuamente ressignificado, estes últimos irão fatalmente exibir sinais de despreparo e falta de traquejo na tênue linha divisória entre chique e vulgar.

É interessante notar que enquanto se pode localizar nas culturas do consumo a presença de certo tipo de economia do prestígio regida pelo acesso restrito a saberes e bens, estas culturas também se constituem a partir de elementos de desejo e fantasia que alimentam o hedonismo na fruição do consumo contemporâneo.

\section{Imagens de sonho e prazer na estetiza- ção do cotidiano pelo consumo}

$\mathrm{Na}$ terceira perspectiva dos estudos do consumo aqui enfocados, a ênfase 
recai sobre o modo como somos afetados pelas imagens e narrativas que se articulam nas culturas midiática e do consumo. Nessa perspectiva, estuda-se a participação dessas retóricas na formação das subjetividades contemporâneas. No incitamento ao prazer estético e emocional pela semiosfera do consumo, tem efeito a mobilização decerto tipo de excitação corporal condizente ao presenteísmo e ao abrandamento da mediação contentora da razão em prol do puro deleite sensível e emocional.

Nesse ideário, pode-se também entender as práticas de consumo no conjunto dos modos de resistência às demandas incessantes das rotinas do trabalho duro, da moral ascética da tradição judaico-cristã que prega a contenção no presente visando a segurança no futuro. A espetacularização da fartura e do prazer da boa vida nas imagens e retóricas do consumo contrasta com a moral da escassez, da limitação dos prazeres e da apologia à vida regrada. Sob o ponto de vista de uma teoria dos afetos, estaria em jogo a mobilização de uma identificação subjetiva coma capacidade de inventar para si uma vida melhor, o que se daria, também, por meio do engajamento certos tipos de consumo como, por exemplo, certas dietéticas e rotinas que integram a densa malha de significados do chamado consumo consciente.

Certas imagens e espaços de consumo convidam o consumidor a entrar na moldura e deixar-se levar pela envolvente promessa de felicidade e bemviver atrelada a transformações advindas no futuro da adoção de práticas e hábitos no presente. Em interessante estudo sobre a potência afetiva de imagens de transformação difundidas, por exemplo, em reality shows nos quais algumas pessoas se submetem a intervenções radicais que alteram de modo drástico a sua aparência, Coleman (2013:23) argumenta, com propriedade, que essas imagens mobilizam um tipo de antecipação de futuro que pode ser extremamente bem sucedido justamente pelo seu caráter afetivo. Em suas palavras:

"as imagens de transformação dizem respeito ao futuro como um potencial, um tipo de futuro que escapa ou ultrapassa as especificidades do planejamento ou a sua localização em um objeto ou produto, um tipo de futuro que envolve o ainda-não. Desse modo, as imagens de transformação são potencialidades e funcionam como possibilidades imateriais, virtuais que podem vir a ser atualizadas. (...) como um potencial, os futuros dessas imagens são pervasivos, atraentes e poderosos porque são afetivos. As promessas feitas pelas imagens de transformação são afetivas por que dizem respeito a esperanças e sonhos de um futuro melhor, engajando o corpo por meio da intensidade do sentimento."6 (grifos no original)

Nos estudos de mídia, a investigação das estratégias de produçãohoje vigentes revela que o entretenimento se apresenta como lógica dominante, perpassando áreas tão diversas quanto o jornalismo, a educação, a religião e a política, entre outras. Por meio da espetacularização nas lógicas do entretenimento, transforma-se qualquer instância do cotidiano em oportunidade para o consumo de marcas, serviços e produtos. Os neologismos tão bem descritos por Bosshart e Hellmüller (2009) refletem a ampla disseminação do entretenimento nas dinâmicas do infotainment, do edutainment, do politainment e afins.

Como ambientes de mobilização e de construção de uma cultura participativa, as redes sociais digitais podem ser enfocadas sob o ponto de vista articulação de estratégias corporativas.A capacidade de conjugar de modo efetivo o fascínio do 
mundo dos espetáculos e a interatividade desses circuitos de comunicação instantânea e ubíqua está na base de estratégias como o buzz e o viral, pedras de toque da estreita imbricação que se configura nessas redes entre comunicação e sociabilidade e negócios. No ambiente comunicacional atual, saturado de apelos publicitários, marcas e corporações investem na criação de estratégias como o advertainment, misto de publicidade e entretenimento concebido para ser decodificado como conteúdo e amplamente compartiIhado e comentado entre pares nas redes digitais. Nas tramas de redes telemáticas cada vez mais ubíquas, as quais também devem ser entendidas como redes afetivas, as interações entre seus mais diversos membros configuram o canal no qual se tece um certo sentido de comunidade.

Outro estratégia desse tipo são as narrativas transmidiáticas, que se espalham em diversas plataformas e ensejam modos e níveis diversos de fruição. Tais estratégias frequentemente incentivam a participação do consumidor fidelizado como fã e valorizado como parte do patrimônio intangível da marca. Certas franquias no mercado globalizado do entretenimento, como Star Wars, por exemplo, tornaram-se emblemáticas na consolidação de um tipo de agente social ligado de modo afetivo, mais pessoal e direto, consolidando o que pode ser denominado como capital emocional.

Do cliente ao fã, do comprador ao colecionador aficionado, do consumidor ao colaborador, do endossante ao divulgador: o competitivo ambiente de negócios enseja forte investimento por parte das corporações na construção afetiva do universo simbólico da marca. O grande produto seria a mobilização afetiva do consumidor e um objetivo tornar indistintos trabalho e lazer nas dinâmicas do consumo.
Um caso exemplar pode ser observado na lkea, marca escandinava do ramo do mobiliário, artigos de cama, mesa e banho, objetos de decoração e utilidades para o lar. A retórica e a imagética corporativa articulam regularmente questões candentes do meio social, tais como a sustentabilidade e as relações de solidariedade como parte integrante da cadeia produtiva. Inovação e resgate de tradições convivem no ideário da marca, que combina de modo paradoxal e bem sucedido características de lazer, sonho e glamour das grandes lojas de departamento com os apelos típicos dos supermercados, como preços módicos, conveniência e praticidade para suprir as necessidades do dia a dia.

Conforme argumenta Bowlby (2000:10) em estudo sobre a invenção do modo moderno de ir às compras, "enquanto a loja de departamentos te convida para entrar, o supermercado te agarra e não te deixa sair ${ }^{7}$ ". A autora reconhece, no entanto, que essas características foram sendo atenuadas com o passar do tempo e muitos supermercados hoje se oferecem também como espaços confortáveis onde se pode passar o tempo de modo agradável, fazendo ali mesmo uma refeição, por exemplo, caso se deseje.

Ao conjugar o agradável e o funcional, o lazer e o trabalho, os prazeres e as demandas envolvidas neste tipo de consumo, a marca sueca pode ser entendida como o epíteto de um modelo de negócios no qual não há venda ou compra ostensiva. No entender da autora, este tipo de proposta comercial é apresentado de modo bem mais sutil no discurso da marca. Em suas palavras, o que existe ali "é o fazer compras como possibilidade - ver e experimentar as coisas, desejos e planos introjetados ${ }^{8}$." Observando-se a maneira estratégica como estão dispostas as diferentes seções de produtos, percebe-se que o consumidor é levado a percorrer um 
trajeto concebido para incluir, necessariamente, toda a extensão do megastore. Durante toda a permanência na loja não se é abordado pela equipe de vendas. Em sua funcionalidade minimalista, o modelo de negócios elimina a mediação do vendedor e a loja-galpão funciona com um número extremamente reduzido de funcionários.

Em nome da economia, que na retórica corporativa da Ikea funciona como argumento de vendas, transfere-se para o próprio consumidor as funções de selecionar os produtos que pretende adquirir, localizá-los no estoque, embalar, transportar e montar cada equipamento em sua residência. Se, por um lado, a experiência de compra procede de acordo com os preceitos do faça-você-mesmo, toda a comunicação da marca enfatiza o apuro profissional e insinua o trabalho colaborativo entre designers suecos e fornecedores localizados em diferentes locais do mundo. Esse discurso mobiliza elementos que visam a legitimação social da marca em diálogo com o contexto social enquanto, simultaneamente, procuram conferir autenticidade por meio das ideias de criatividade e funcionalidade enraizadas em patrimônio cultural regional.

Examinando-se um catálogo da Ikea - impresso ou em formato digital interativo - ou ainda em suas bem cuidadas ações promocionais, depreende-se com clareza que a consolidação deste universo simbólico é finamente trabalhada com investimentos de grande monta.Em 2013, o site institucional foi transformado durante dois meses em um 'mercado das pulgas' 9 onde os clientes $^{10}$ podiam comercializar online qualquer mobília da marca para a qual não tivessem mais utilidade. Ao promover uma alternativa ao desperdício e dialogar com a mobilização social em prol da ecologia, a campanha procurou ainda subverter o senso comum de que por serem baratos, os produtos da loja sueca teriam baixa durabilidade.

No mote da campanha atual no Reino Unido ${ }^{11}$, a promessa de dentro em breve passar a trabalhar apenas com iluminação a base de LED $^{12}$ claramente articula a imagem da empresa à causa da preservação do meio ambiente.Entende-se neste tipo de retórica a intenção de vincular a marca ao rol de valores que circulam no meio social e que são caros ao consumidor contemporâneo, como a responsabilidade social corporativa e o bem estar do planeta diante da escassez de recursos naturais.

Tendo examinado as três principais perspectivas adotadas pelos estudiosos do consumo, podemos argumentar que cada uma a seu modo tem contribuído para a apreensão crítica do multifacetado fenômeno que nomeia a nossa época. Em La era del consumo, Alonso (2005:99) ensina que entender o contexto social onde está inserido o consumidor, compreender os usos sociais dos bens de consumo e a complexa simbologia que cada um deles mobiliza significa conceber o consumo como "uma mescla realista de manipulação e liberdade de compras, de impulso e reflexão, de comportamento condicionado e uso social dos objetos e símbolos da sociedade de consumo".

\section{Considerações Finais}

Não é novidade afirmar que a cultura material tornou-se ubíqua e pervasiva nas sociedades contemporâneas. Conforme ensina Sassatelli (2007:4), "o conceito de cultura material vai além da distinção entre material e simbólico, e insinua que os objetos fazem parte de um sistema aberto de significados, que requer a intervenção dos atores [sociais] para adquirir sentido"13. 
$\mathrm{Na}$ primeira fase da industrialização, as marcas tiveram como função conferir identidade a bens produzidos em massa. A linguagem publicitária procurava sugerir confiança na idoneidade das marcas por meio de estratégias variadas. No campo da alimentação, por exemplo, referências ao processo caseiro de preparo. O marketing de novos tipos de bens de consumo até então desconhecidos e que de certa forma desestabilizavam as rotinas estabelecidas, convocava a autoridade da ciência para construir um discurso persuasivo de cunho didático acerca dos seus benefícios.

A mediação das marcas entrava em cena para de certa forma moderar a grande transformação trazida pela industrialização e a urbanização nas práticas de consumo. Conforme Sassatelli (2007:5) "o fenômeno do branding claramente alude à importância da lealdade e do vínculo pessoal e personalizado no mercado de massa"14. A forte identificação entre vendedores e compradores nos mercados locais de pequenos povoados foi sendo substituída pela impessoalidade nos modernos espaços de consumo.

Paralelamente, na associação entre compras e passeio, os bens de consumo como produtos culturais e parte integrante da vida moderna.

Ao analisar a participação do consumo no modo de vida moderno, Featherstone (2007: xiv), argumenta que

O direito ao consumo passou a ser visto como uma recompensa pela expansão da indústria. A vida moderna tornou-se associada ao suprimento infindável de novos bens, para equipar as casas mais eficientes com equipamentos de "economia no trabalho", juntamente com o acesso a novos es- tilos e modas, em conjunto com uma maior ênfase na 'personalidade' e na apresentação de si por meio de técnicas como a cosmética e a manutenção da boa forma física. ${ }^{15}$

Como decorrência da crise do petróleo na década de 1970, mudanças nos processos produtivos levaram ao progressivo deslocamento do modelo serial fordista para o modelo flexível de produção limitada e sob demanda na montadora japonesa Toyota, que se revelou mais adequado aos tempos de crise.Cresce a preocupação com os limites do modelo de expansão capitalista e os riscos ambientais decorrentes da poluição e do eventual esgotamento dos recursos naturais. As dimensões éticas e propriamente políticas das práticas de consumo entram na ordem dia e, como vimos, são absorvidas pelas retóricas do consumo por meio de diferentes estratégias.

A crescente segmentação dos mercados e a hipersaturação de mensagens publicitárias na mídia, assim como nos espaços urbanos ${ }^{16}$, enseja a fase de sondagem mercadológica dos interesses e desejos do consumidor cujos hábitos convivem com certa predisposição à novidade fomentada como valor no ideário neoliberal vigente.

Outro recurso para lidar com o que poderia ser descrito como certo esgotamento de formas mais tradicionais de publicidade tem sido a ênfase na criação de experiências com forte apelo emocional nas retóricas da comunicação publicitária. A associação entre comunicação, consumo e afetividade foi discutida com mais detalhe em trabalho anterior (Castro 2013). Nas tramas de redes telemáticas cada vez mais ubíquas, as quais também devem ser entendidas como redes afetivas, as interações entre pares configuram o canal no qual se tece certo sentido de comunidade.Tam- 
bém tenho chamado a atenção para as invisíveis porém lucrativas operações de prospecção e mineração das nossas interações on line para fins comerciais (Castro 2014).

$\mathrm{Na}$ assim chamada web 2.0 , comunicação, sociabilidade e consumo se entrecruzam. Para Alex Primo (2007:1), a expressão refere-se "não apenas a uma combinação de técnicas informáticas mas também a um determinado período tecnológico, a um conjunto de novas estratégias mercadológicas e a processos de comunicação mediada por computador". O pesquisador chama a atenção para a emergência do consumidor que é simultaneamente coprodutor e distribuidor de conteúdos nesta "segunda geração de serviços online que se caracteriza por potencializar as formas de publicação, compartilhamento e organização de informações, além de ampliar os espaços para a interação entre os participantes" (idem)nas redes sociais digitais.

Adilson Citelli (2009: 195) oferece uma interessante análise da etimologia comum às palavras consumo, consumismo, consumidor, consumação lembrando sua origem comum no latim consumere, que "traz consigo Eros e Tânatos, (...) glória e infortúnio". Com saborosa verve, o estudioso prossegue:

Daí muitas vezes a euforia efêmera de guiar um carro que não poderá ser pago, de flanar por um apartamento cujas prestações se acumulam (...) e terminam por dar cabo (...) aos devaneios de uma vida confortável. O consumere, ademais, pode trazer consigo a satisfação do sonho traduzido em fato, em encontros que ajustam ter e ser."

É bem verdade que frustração e satisfação compõem um equilíbrio precário nas dinâmicas de consumo. A des- peito da provocativa sedução hedonista das linguagens do consumo e de suas mirabolantes artimanhas promocionais, estão latentes os complexos jogos de inclusão e exclusão na lógica cultural do consumo.

Tornar-se consumidor está longe de ser um processo natural. Como fenômeno social e cultural, o consumo envolve doses variadas de desejo e necessidade, impulso e cálculo, o risco da ousadia e a segurança do bom senso, mescla de alegria e sofrimento. Tornar-se consumidor envolve conhecimento, atitude, capacidade reflexiva.

Saber sobre nossos direitos e deveres nos inescrutáveis contratos comerciais, a procedência dos bens, sua composição e seus modos de produção, as relações de cooperação e exploração envolvidas nas cadeias produtivas, estes são apenas alguns dos elementos que tem motivado a mobilização de organizações de consumidores em todo o mundo. Nesses modos de ativismo que têm como objetivo influenciar na definição de políticas públicas que, por exemplo, criminalizem o trabalho escravo e tornem obrigatórias as informações sobre a presença (ou não) de transgênicos nas embalagens dos supermercados, apresenta-se de modo claro a imbricação entre consumo e cidadania em nossos conturbados dias.

No prefácio especialmente escrito para a segunda edição de Cultura do consumo e pós-modernismo, Featherstone (2007) ressalta o protagonismo do consumo nas cadeias de interdependência num mundo marcado pela desigualdade. Em países desenvolvidos, o desmantelamento do estado de bem estar social promovido pela lógica neoliberal ocasiona drástica redução da qualidade de vida das parcelas mais vulneráveis da população e contribui para aumentar 
o fosso entre ricos e pobres. Nos países emergentes, políticas de microcrédito e a instituição pelo Estado de práticas assistenciais e ações sociais ${ }^{17}$ de fomento ao consumo são implementados como forma de estimular a mobilidade social dos mais pobres e sua participação cidadã na economia. Enquanto isso, uma seleta casta de bilionários se movimenta com desenvoltura nos cenários transnacionais do consumo, adquirindo propriedades que jamais irão usar, apenas como forma de investimento.

Há algumas décadas, Garcia Canclini (1996) lançou como provocação a ideia que "o consumo serve para pensar". Para os desavisados, pareceu tratar-se de um chiste. Para outros, um chamado à reflexão e à pesquisa. A cada dia surgem novos ângulos para que se possa examinar e compreender - quiçá transformar as culturas do consumo. Considerando a situação estratégica do Brasil nos blocos emergentes econômicos, políticos e culturais no contexto da globalização em curso, essa discussão se torna tão necessária quanto urgente.

\section{Bibliografia}

ALONSO, Luiz Enrique. La era del consumo. Madri: Siglo XXI, 2005.

BACCCEGA, Maria Aparecida. Comunicação e culturas do consumo. São Paulo: Atlas, 2008.

BOSSHART, L. e HELLMÜLLER,L.Pervasive entertainment, ubiquitous entertainment. Communication Research Trends, vol. 28, n. 2, p. 3 19,2009 .

BOWLBY, Rachel. Carried away: the invention of modern shopping. Londres: Faber and Faber, 2000.

CASTRO, Gisela G. S. Entretenimento, subjetividade e consumo nas redes digitais: mobilização afetiva como estratégia de negócios. IN: BARBOSA, Marialva e MORAIS, Osvando (orgs.). Comunicação em tempos de redes sociais: afetos, emoções subjetividades. São Paulo: Intercom, 2013.

Mobilizing the consumer as a partner in social networks: reflections on the commodification of subjectivities. IN: ARCILA, Carlos. CALDERÍN, Mabel e CASTRO, Cosette (eds.). An overview of digital media in Latin America. London: University of West London Press, 2014.

CITELLI, Adilson. Pensando o consumo entre a comunicação e a cultura. Comunicação, Mídia e Consumo, vol. 6, n 15, 2009.

COLEMAN, Rebecca. Transforming images: screens, affects, futures. Londres e N. York: Routledge, 2013.

FEATHERSTONE, Mike. Consumer culture and postmodernism. Londres, Thousand Oaks (CA), Nova Déli e Singapura: Sage,Segundaedição, 2007.

Perspectives on consumer culture. Sociology, vol. 24, no. 1, 1990.

Consumer culture: an introduction. Theory, Culture \& Society, vol. 1, no.4, 1983.

GARCIA CANCLINI, Nestor. Consumidores e cidadãos: conflitos multiculturais da globalização. Rio de Janeiro: Editora UFRJ, 1996.

PRIMO, Alex (org.). Interações em rede. Porto Alegre: Sulina, 2013.

SASSATELLI, Roberta. Consumer culture: history, theory and politics. Londres: Sage, 2007.

SODRÉ, Muniz. Eticidade, campo comunicacional e midiatização. IN: MORAES, Denis de (org.). Sociedade midiatizada. Rio de Janeiro: Mauad, 2006.

1 Docente e Pesquisadora do PPGCOM ESPM, São Paulo. Pós-doutoranda no departamento de Sociologia do Goldsmiths College, Londres, onde desenvolve pesquisa sobre o envelhecimento nas culturas midiática e do consumo sob supervisão de Mike Featherstone.

2 Cabe aqui uma ressalva a esta concepção clássica e altamente negativa do entretenimento como alienação na 
frivolidade da divertimento. Nem todo o entretenimento é divertido (vide o jogo de xadrez, por exemplo). Do mesmo modo, nem toda a diversão (como certa programação de televisão) é necessariamente superficial e alienante. $O$ trabalho dos teóricos da Escola de Birmingham influenciaram enfatizaram o caráter ativo do processo de recepção e consumo. Os estudos da rede Obitel (Observatório Iberoamericano de Ficção Televisiva) sobre a telenovela deixam claro o seu papel como crônica de costumes e narrativa da nação, assim como sua participação na disseminação de temas, por vezes polêmicos, no debate público.

3 Em versão livre: conteúdo gerado pelo usuário.

4 De vinho do porto, por exemplo.

5 É interessante o papel atribuído ao colecionador em certas culturas do consumo. Como fã e especialista, o colecionador conectado em redes sociais digitais pode funcionar como parceiro na divulgação de marcas e produtores, em níveis mais ou menos explícitos de colaboração.

6 No original: "images of transformation involve the future as potential, a future that escapes or exceeds the specifics of planning or its location within an object or a product, a future that involves the not-yet. Images of transformation are thus potentialities in that they function as immaterial possibilities/virtuals that might be actualized. (...) as potential, the futures of images of transformation are pervasive, appealing and powerful because they are affective. The promises made by images of transformation are affective in that they address hopes and dreams of a better future, and engage the body through the intensity of feeling." Tradução livre minha.

7 No original (p. 10): "Where the department store invites you in, the supermarket grabs you and won't let you out". Tradução livre minha.

8 No original (p. 11): "this is shopping as possibility - the sight and feel of things, the embedding of desires and plans." Tradução livre minha.

9 Bastante comuns na Europa, nesses mercados populares vende-se (e compra-se) todo o tipo de material de segunda mão a preços módicos. É interessante notar o cruzamento pouco usual entre os circuitos oficiais e alternativos de consumo promovido pela campanha.

10 A campanha 'Segunda Mão'foi criada pela agência SMFB Olso, e veiculada na Noruega. Vertido para o inglês, o comercial para a TV pode ser conferido em www. youtube.com/watch?v=GmA_1bdHjHk (último acesso: abril 2014).
11 IKEA Forest, comercial para televisão disponível em www.yotube.com/user/ikeauk (último acesso: abril 2014).

12 Light Emitting Diode, ou diodo emissor de luz é uma tecnologia de baixo consumo de energia na geração de luz.

13 No original: The concept of material culture goes beyond the material/symbolic distinction, and underlines that objects are part of a system of openmeanings which require the intervention of actors to become meaningful. Tradução livre minha.

14 No original: the phenomenon of branding clearly adumbrates the power of loyalty and personal(ized) attachments in the mass market. Tradução livre minha.

15 No original: The right to consumption became increasingly seen as the reward for industrial expansion. Modern living became associated with the endless supply of new goods, to furnish more efficient homes filled with 'labour saving' devices, along with the access to new styles and fashions, coupled with a greater emphasis upon 'personality' and the presentation of self via techniques of grooming and body maintenance. Tradução livre minha.

16 A esse respeito, compartilho minha surpresa ao visitar no centro-oeste brasileiro o imenso e belíssimo Parque Nacional do Jalapão (TO) e encontrar, nas proximidades de cada pequeno povoado, a presença recorrente e espalhafatosa de placas anunciando certa marca transnacional de refrigerantes. Como contraste, temos a Lei Cidade Limpa em vigor em cidades como São Paulo, restringindo o uso comercial do espaço público. O Rio de Janeiro convive com a sistemática mercantilização do patrimônio tornado vitrine, como as barracas de sol padronizadas em cada praia, com as cores e o logo de uma marca de cerveja.

17 Como o Programa Bolsa-Família, por exemplo. Note-se, a esse respeito, que em sua primeira campanha presidencial Dilma Roussef tinha como promessa "transformar cada brasileiro em consumidor".

18 Por meio da cobertura da imprensa, pode-se observar a preocupação crescente nas principais cidades do mundo com o fenômeno dos imóveis de alto luxo arrematados por oligarcas internacionais que os mantêm desocupados e ociosos. 